\title{
Study of Dance Entertainment Using Robots
}

\author{
Kuniya Shinozaki ${ }^{1}$, Akitsugu Iwatani ${ }^{2}$, Ryohei Nakatsu ${ }^{1}$ \\ ${ }^{1}$ Kwansei Gakuin University, School of Science and Technology \\ 2-1 Gakuen, Sanda 669-1337, Japan \\ ${ }^{2}$ Universal Studios Japan \\ Osaka, Japan
}

\section{Introduction}

The research and development of various types of robots is actively being pursued, especially in Japan. It is expected that the Aichi EXPO robot shows and robot exhibitions would be one of the most popular shows. There are several reasons why there is a big boom for robots right now. One of these is that robots have physical bodies and because of this, communications between robots and human stretch beyond the communications between computer characters and humans. Since the capabilities of robots to date are insufficient for supporting us in various aspects of our lives, however, one of their major applications is entertainment.

The role of entertainment in our daily lives is a very important one. Entertainment relaxes us, pleases us, and thus contributes to our mental health. Although there are various types of entertainment, the positioning of dance is unique as dancing activates both our body and our brain. Furthermore, dance can be considered a kind of communication. E It is well known that there are two types communication: verbal and nonverbal, and dance is one of the most sophisticated nonverbal communication methods.

. If we could develop a robot that can dance, it would be very interesting from various o points of view. First, the dancing robot might become a new form of entertainment. To O watch humans dancing is one of the well-established forms of entertainment, but if we .1 could show people various types of dance achieved by robots, that would be a new type of entertainment. Second, we would be able to develop a new type of communication $\xi$ with computers. The interactions/communications between humans and computers o have long been studied, with most of the research treating communications using 疋 speech, facial expression, and gestures commonly used in our daily communications. $\underset{\pi}{\pi}$ Although these are important research themes, it is necessary for us to tackle the problem from a different aspect. Because dance is a special type of communication, by study\& ing a dance robot, it is possible that we could develop a new type of communication between humans and robots.

Based on the above considerations we have commenced research on robots that can dance. $\underset{\mathcal{D}}{\mathcal{O}}$ In this paper, we clarify the relationship among entertainment, humans, and robots. We also describe an example of a robot that can dance. 


\section{Entertainment and Robot}

\subsection{Entertainment}

There are so many aspects to consider and discuss concerning entertainment (Callois, 1958)(Csikszentmihalyi,1975). One of the most important aspects may be the existence of sides: the side to entertain and the side to be entertained. Although these two sides might exchange their positions with one another depending on the situation, the existence of performers and spectators is an absolute condition for entertainment. Many types of entertainment have characteristics whereby people can become both entertainers and spectators. In the case of baseball, for example, people can play baseball and thus entertain themselves, and they may also enjoy it by watching professional baseball games as spectators. Dance belongs to this category. People sometimes attend theaters to watch good dance performances and may sometimes go to dance clubs or discos to enjoy dancing.

Furthermore, entertainment could be classified into two categories when looking it from a different aspect. One is a real-time type, where performers or entertainers are in face-to-face mode with spectators. Good examples are plays and/or concerts at a theater. The other is the non-real-time type. This includes reading books and watching movies. The advantages and disadvantages of each type are listed below.

Real time type:

Advantages

-A performer can observe and feel a spectator's reaction.

-A spectator can enjoy the feeling of presence.

Disadvantage

-When a performer makes a mistake, it is difficult to redo the action.

Non real-time type:

Advantages

-Prior editing of the performance is possible so that a perfect performance can be shown.

-It can be repeated any number of times, at any time.

-Prolonged preservation is possible.

Disadvantage

-It is difficult for spectators to have the feeling of presence.

Following this classification, dance basically belongs to real-time entertainment. In the case of robot dancing, however, as will be described later, its positioning is somewhat special.

\subsection{Positioning of entertainment robot}

In recent years the robot has become a center of attention (Levy, 2005). The dog-type robot called AIBO has attracted a lot of people (Golubovic et al., 2003)(Ishimura et al., 2003)(Kerepesi et al., 2006), especially women and aged people who wanted to have a pet. Also, a walking robot called ASIMO by Honda surprised many people by its walking demonstration (Ishimura et al., 2003). In addition to these pioneers, currently various types of humanoid and pet robots are being studied and developed in many universities, company laboratories, and venture companies. Furthermore, various demonstrations, shows, and exhibitions are being held, with performances as a humanoid robot's offering relief, dancing, fighting, among others (Nakaoka, 2003)(Shiratori, 2004).

However, there is still the possibility that these are temporary phenomena and sooner or 
later the boom will subside. Although it is expected that in the future these robots will help us in various aspects of our daily lives, so far their capabilities are very limited. For example, we expect that at homes they will assist aged people by helping them to walk, bathe, and so on. At present, however, it is sill very difficult to install one of these tasks onto a robot, one reason being that robots cannot behave intelligently, making it difficult at best for us to rely on them. Another problem is that it is necessary for them to have high physical strength yet at the same time delicate behaviors if we want them to really be useful. For these reasons still there is only a small market for humanoid/pet robots.

To break through this barrier, entertainment is expected to be a good application area for robots (Nakatsu \& Hoshino, 2003). With the above-mentioned entertainment robot there are various ways for users to enjoy themselves, such as creating, operating, showing, and watching. In the case of entertainment, it is not necessary for a robot to have a strong physical power; what it should do is to entertain us by its behaviors and interactions with us. Thus it would be appropriate for us to focus on the application of robots to entertainment. Although there are various types of entertainment, here we focus on dance.

One main reason we choose dance as entertainment by robots is that dance is one of the most sophisticated forms of entertainment. Based on the considerations described in Sections 3.1, what would be the role of robots in dance entertainment? One significant point is that a dancing robot would make it possible for us to become both entertainers and spectators. To the extent that we watch a robot dancing, we are spectators; on the other hand, it is expected that many people would want to install dance motions onto their robots and would want to show their robot motions to other people. In this case they are entertainers.

In distinguishing between real-time entertainment and non-real-time entertainment, again dance robots feature significant characteristics. Basically, if we want to show people the robot dancing, we have to install the dance actions beforehand, which means that the robot dance is non-real-time entertainment. Meanwhile, by developing interactive capabilities, the robot would perform impromptu dancing behaviors. For example, if the robot could recognize a request from one of the spectators, it could change the dance depending on the request. Or if it could sense the mood/atmosphere of the spectators, it could adapt its dancing behaviors depending on the sensing results. This means that the dance robot could give us a sort of variable entertainment that ranges between real-time and non-real-time entertainment.

\section{Humanoid Robot and Its Dance Entertainment}

\subsection{The function and specification of a humanoid robot}

There are already several humanoid robots available on the market. Among them we have selected a humanoid robot developed by Nirvana Technology, on which we will try to install dance motions. Figure 1 shows the appearance of the robot. The moving range for each servomotor used for the robot is $180^{\circ}$. The range of movement assigned to each servomotor is shown in Fig. 2 and Table 1.

The $x, y$, and $z$ axes are set to the erect state, and rotation of the circumference of each axis is considered as roll, pitch, and yaw. Each positive and negative rotation direction is set as plus and minus by the right screw law. The movement range for each joint is shown in Table 1.

The various motions the robot can perform can be designed and produced on a PC using a motion editor realized by software dedicated to motion creation and editing. Figure 3 shows 
the motion editor's interface.

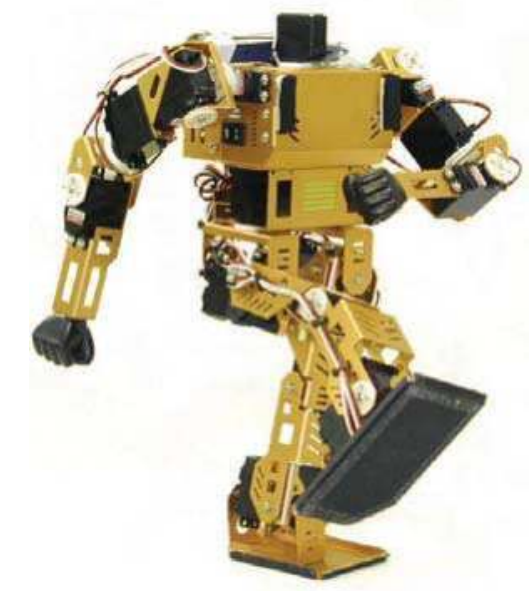

Fig. 1. An example of a humanoid robot.

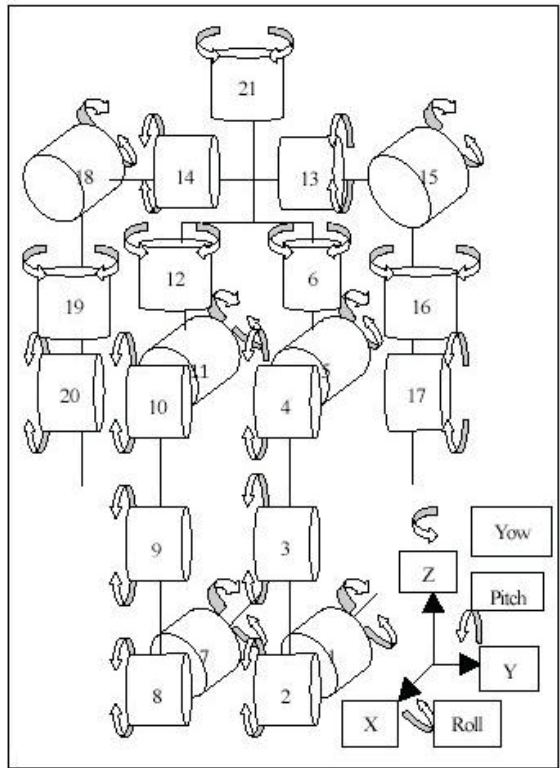

Fig. 2. The movable range of the servomotors.

\subsection{Examples of performance by robot}

As preparatory exercises for the design and development of dance motions, we have created several specific motions. Figure 4 illustrates Tai-chi motions we have created for the robot. In addition, Figs. 5 and 6 respectively display some of the robot actions dedicated to a cheering action, Japanese traditional dance action, and an action imitating a famous Japanese singer. 


\begin{tabular}{|c|c|c|c|c|c|}
\hline Number & + (1) & +7 & Number & $+(1)$ & (1) \\
\hline 1 & 80 & 80 & 13 & 70 & 100 \\
\hline 2 & 60 & 90 & 14 & 70 & 100 \\
\hline 3 & 135 & 0 & 15 & 100 & 15 \\
\hline 4 & 60 & 120 & 16 & 10 & 120 \\
\hline 5 & 80 & 80 & 17 & 0 & 155 \\
\hline 6 & 50 & 50 & 18 & 15 & 100 \\
\hline 7 & 80 & 80 & 19 & 120 & 10 \\
\hline 8 & 60 & 90 & 20 & 0 & 155 \\
\hline 9 & 135 & 0 & 21 & 60 & 60 \\
\hline 10 & 60 & 120 & & & \\
\hline 11 & 80 & 80 & & & \\
\hline 12 & 50 & 50 & & & \\
\hline
\end{tabular}

Table. 1 . The moving range of the robot.

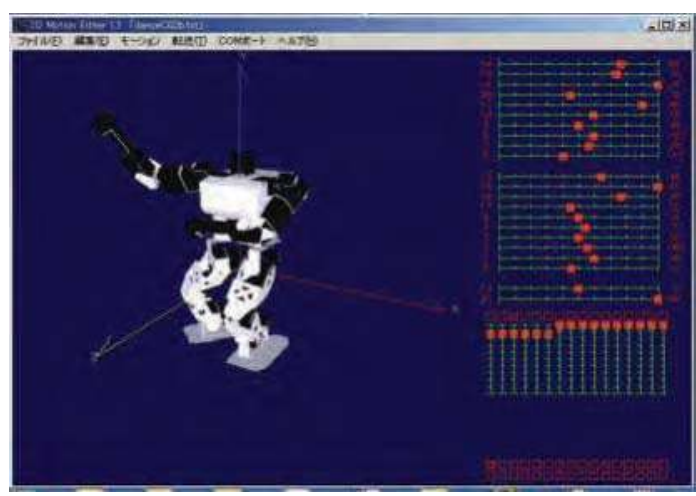

Fig. 3. Motion Editor.

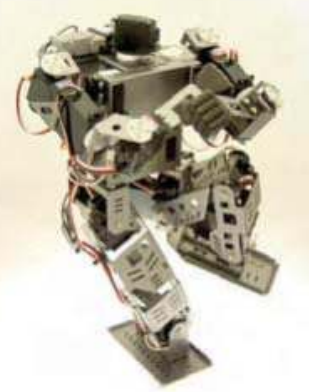

Fig. 4. Form of Tai-Chi. 


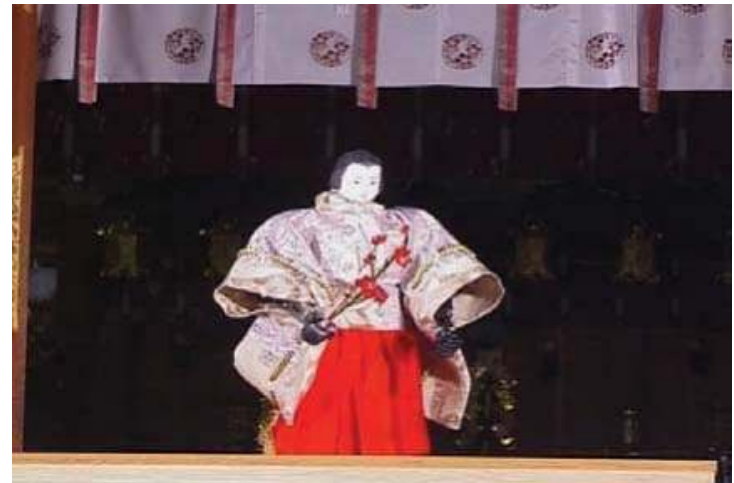

Fig. 5. Japanese Dance.

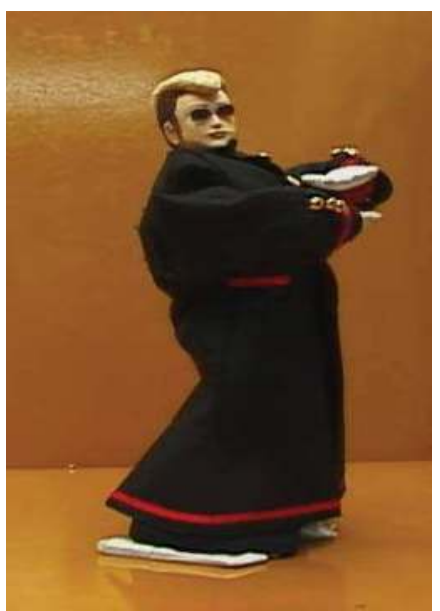

Fig. 6. Japanese Cheer boy.

\section{Realization of the Dance Performance by the Robot}

\subsection{Definition of dance}

It is difficult to define a dance. As already indicated, there is the side to entertain and the side to enjoy entertainment, and dance, especially, contains both of these features. From the perspective of a dancer it is to entertain, and from the side of a spectator, it is to watch and enjoy. These features mean that dance could develop itself into a communication medium with the external world. Moreover, dance has the characteristic of being a pleasure to create, perform, and watch. Each of these factors leads to improvisational expression, making a work and appreciating it (Laban, 1980). Improvisational expression is not only the process of creating a work; it also involves the joy of the expression itself. It is based on the momentary dance act and is full of energy, individuality and freshness that are not present in the elaborated work.

Making a work contains the pleasure of adhering to the content that should be expressed, repeating a device and improving it gradually.

Appreciation means that completion of a work by an entertainer is interpreted, with the spectator having the same feelings and sympathies as the entertainer. 


\subsection{The subject of dance operation by the robot}

One important issue for the dancing robot is whether it can dance in accordance with a rhythm. Generally, the tempo of music that can fit a rhythm is about 140 BPM ( beats per minute ), and the beats are usually arranged as sets of four beats in many cases. A rhythm of 140 BPM has 140 standard notes in one minute; therefore, one beat lasts about 0.4 seconds The software that can control the shift between pauses in the shortest period of 0.1 seconds can create the motion, thus the number of pauses that can be added within one beat is at most four. A robot's dance must fit a rhythm within this constraint.

Another issue is whether the robot can actually attain a level of movement that can be called a dance. A dance uses body expressions as nonverbal communication and transmits them to spectators, so the message conveyed by the dance would vary like body language or a work of art, with originality and creativity. Therefore, understanding and misunderstanding might exist together between the senders and the receivers of dance information. Consequently, smooth transfer of the contents may sometimes become difficult at the expression stage. To alleviate the problem, a device is required to express dance that can create sympathy within the mind of any spectator.

\subsection{The generation method of dance motion}

One author of this work, Mr. Iwatani, works as a dancer at Universal Studios Japan. As we thought it essential to include a dancer among our members, we asked him join the group and start a collaboration. Based on discussions with him, rocking and popping motions were chosen as robot's main dances.

Popping is a term for the dance style that makes the body flip by putting power into the body momentarily and combining this power with pantomime, animation, etc. according to a rhythm.

Rocking is a term for a dynamic dance style with a rhythm picking of 16 beats, the combination of lock, stops a motion momentarily and determines a pause, pointing by the fingertip and step etc. There is a fundamental motion but the style changes delicately depending on the person and place.

Both dances consist of various segments of moves generated in accordance with rhythms. The sophisticated selection and concatenation of each move makes it possible for the dance action to be recognized as art. Furthermore, each move is generated by connecting various shorter segments called poses. These poses and moves respectively correspond to key frames and motions of the robot. This basic concept simplifies the transfer process of the human dancing image into robot motions.

Several examples of the dance actions performed by the dancer are shown in Fig. 7. Also several examples of the robot dance action segments we have developed are shown in Fig. 8.

\section{Conclusion and Further Research}

In this paper, we have proposed dancing as a new application area for humanoid robots. First, we investigated the meaning of entertainment and clarified several distinctive characteristics of it. Then we examined the role of robots in the area of entertainment. By showing that dance performed by robots have several significant characteristics, we indicated that robot dance could become a new type of entertainment. Following that, we described several features required for a dance robot to be a success. As an example of a humanoid robot that can be used 
to apply dance actions, we have chosen a humanoid robot built by Nirvana Technology.

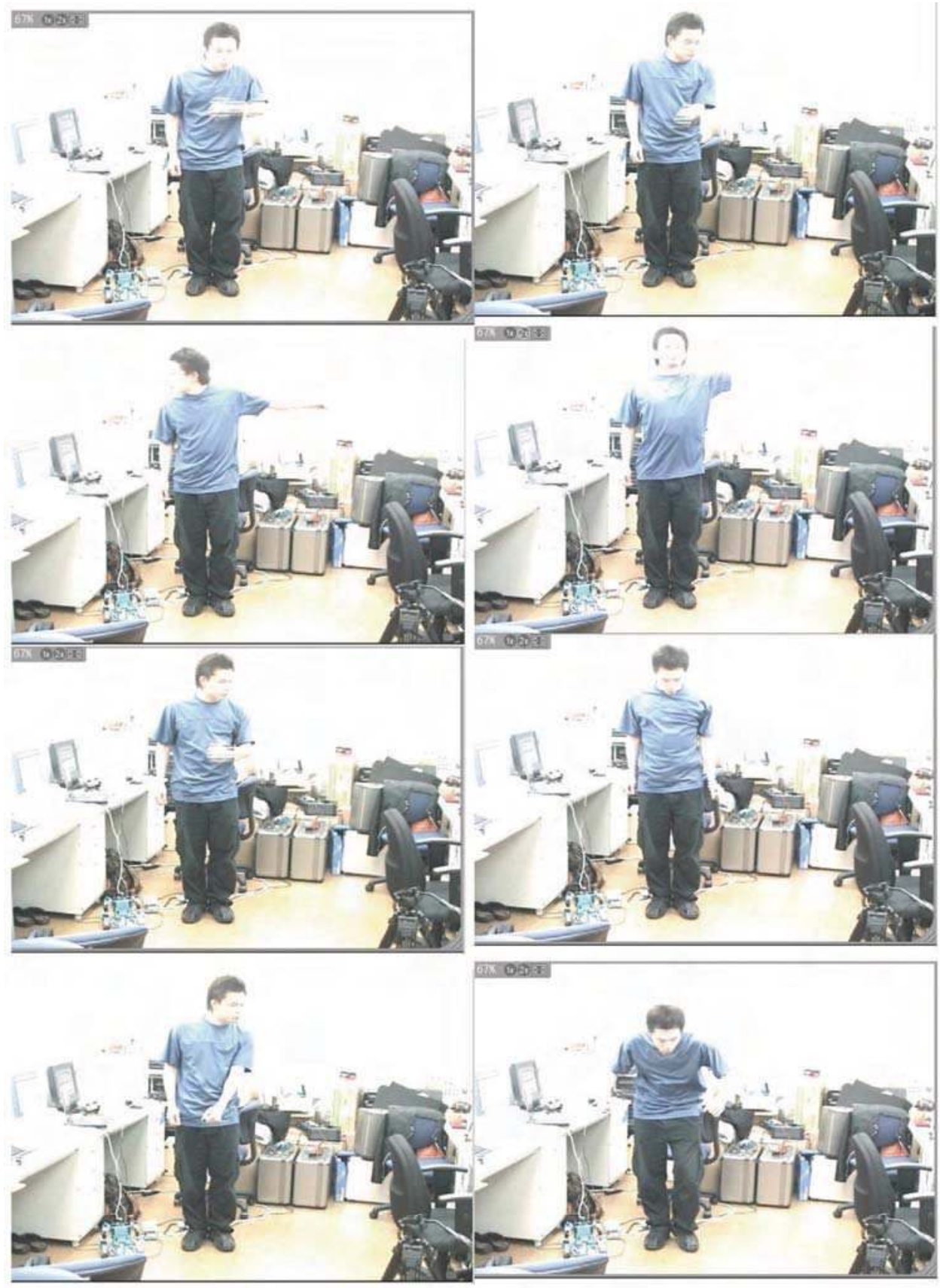

Fig. 7. An example of the actual dance by the human. 

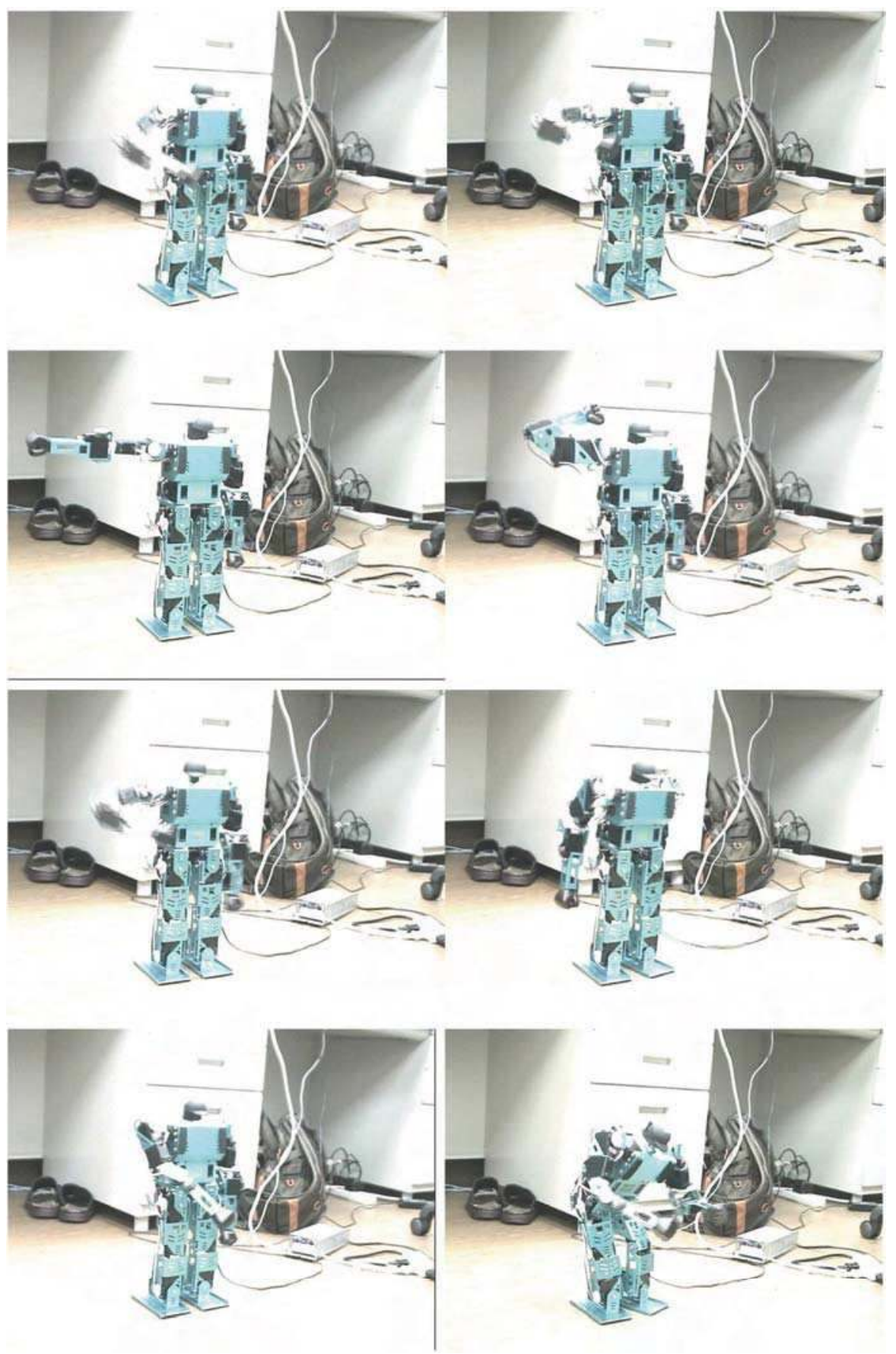

Fig. 8. An example of the actual dance by the robot. 
The most delicate point in our research is to decide and select appropriate short dance actions called dance segments. By merging and concatenating various kinds of dance segments it would be possible for our robot to perform many different dance actions. To achieve this we have started a collaborative study with a dancer, and based on discussions with him we are now in the process of collecting dance motions into a group of dance segments

There are many research items remaining for further study. One is the evaluation of dance actions performed by the robot. In our laboratory, we have started measuring human brain activity by applying a system called NIRS. The same experimental methodology could be applied for the case of robot dancing. We plan to measure our brain activity while watching the robot dance. In addition, we want to compare these data with other data such as measurement results while playing video games, gambling, reading books, or watching TV and movies.

Furthermore, we want to examine whether robot dancing could be applied for image training. It is well known that imagination includes the same function as real body training. If we imagine a body movement in our brain, the signal is the same as the one in the case of a real body action command transmitted to muscles through neurons. If such training is repeated, the neural network corresponding to the action will be strengthened, thus a command for the action can be more efficiently processed. This shows that watching the robot dancing and imagining those dance movements may be useful in activating our bodies.

It has also been pointed out that watching sophisticated dance motions can relax us and release us from fear or sadness. Utilizing this feature, dance therapy, which incorporates dance movements for psychotherapy, has been conducted since the 1940s and remains popular. If we could apply robot dancing to the dance therapy, robots will have a brighter future.

\section{References}

R. Callois, (1958). Les Jeux et les Hommes, Paris: Callimard.

M. Csikszentmihalyi, (1975). Beyond Boredom and Anxiety: Experiencing Flow in Work and Play, Jussey-Bass Inc. Publishers.

D. Golubovic, B. Li and H. Hu, (2003), A Hybrid Software Platform for Sony AIBO Robots, RoboCup 2003: Robot Soccer World Cup VII, 478-486.

T. Ishimura, T. Kato, K. Oda and T. Ohashi, (2003), An Open Robot Simulator Environment, RoboCup 2003: Robot Soccer World Cup VII, 621-627.

A. Kerepesi, E. Kubinyi, G.K. Jonsson, M.S. Magnusson and A. Kiklosi, (2006), Behavioural Comparison of Human-Animal (Dog) and Human-Robot (AIBO) Interactions, Behavioural Processes, Vol.73, No.1, 92-99.

R. Laban, (1980). The Mastery of Movement, Macdonald and Evans; 4th ed., revised and enlarged edition.

D. Levy, (2005). Robots Unlimited: Life in a Virtual Age, A. K. Peters, Ltd.

S. Nakaoka, A. Nakazawa, K. Yokoi, H. Hirukawa and K. Ikeuchi, (2003). Generating Whole Body Motions for a Biped Humanoid Robot from Captured Human Dances, IEEE 2003 International Conference on Robotics and Automation.

R. Nakatsu and J. Hoshino (ed.), (2003), Entertainment Computing - Technologies and Applications -, Kluwer Academic Publications.

T. Shiratori, A. Nakazawa, K. Ikeuchi, (2004). Detecting Dance Motion Structure through Music Analysis, Proceedings of IEEE International Conference on Automatic Face and Gesture Recognition.

T. Wama, M. Higuchi, H. Sakamoto and Ryohei Nakatsu (2004), Realization of Tai-chi Motion Using a Humanoid Robot, Entertainment Computing, Springer LNCS, 14-19. 


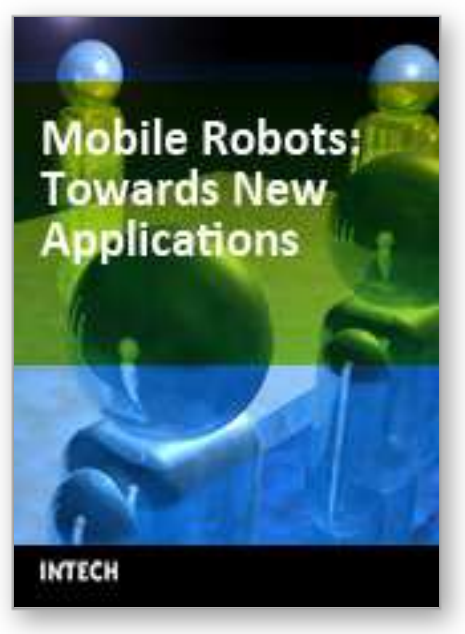

\author{
Mobile Robots: towards New Applications \\ Edited by Aleksandar Lazinica
}

ISBN 978-3-86611-314-5

Hard cover, 600 pages

Publisher I-Tech Education and Publishing

Published online 01, December, 2006

Published in print edition December, 2006

The range of potential applications for mobile robots is enormous. It includes agricultural robotics applications, routine material transport in factories, warehouses, office buildings and hospitals, indoor and outdoor security patrols, inventory verification, hazardous material handling, hazardous site cleanup, underwater applications, and numerous military applications. This book is the result of inspirations and contributions from many researchers worldwide. It presents a collection of wide range research results of robotics scientific community. Various aspects of current research in new robotics research areas and disciplines are explored and discussed. It is divided in three main parts covering different research areas: Humanoid Robots, Human-Robot Interaction, and Special Applications. We hope that you will find a lot of useful information in this book, which will help you in performing your research or fire your interests to start performing research in some of the cutting edge research fields mentioned in the book.

\title{
How to reference
}

In order to correctly reference this scholarly work, feel free to copy and paste the following:

Kuniya Shinozaki, Akitsugu Iwatani and Ryohei Nakatsu (2006). Study of Dance Entertainment Using Robots, Mobile Robots: towards New Applications, Aleksandar Lazinica (Ed.), ISBN: 978-3-86611-314-5, InTech, Available from:

http://www.intechopen.com/books/mobile_robots_towards_new_applications/study_of_dance_entertainment_u sing_robots

\section{INTECH}

open science | open minds

\author{
InTech Europe \\ University Campus STeP Ri \\ Slavka Krautzeka 83/A \\ 51000 Rijeka, Croatia \\ Phone: +385 (51) 770447 \\ Fax: +385 (51) 686166 \\ www.intechopen.com
}

\author{
InTech China \\ Unit 405, Office Block, Hotel Equatorial Shanghai \\ No.65, Yan An Road (West), Shanghai, 200040, China \\ 中国上海市延安西路65号上海国际贵都大饭店办公楼 405 单元 \\ Phone: +86-21-62489820 \\ Fax: +86-21-62489821
}


(C) 2006 The Author(s). Licensee IntechOpen. This chapter is distributed under the terms of the Creative Commons Attribution-NonCommercial-ShareAlike-3.0 License, which permits use, distribution and reproduction for non-commercial purposes, provided the original is properly cited and derivative works building on this content are distributed under the same license. 